\title{
Skin Staple
}

National Cancer Institute

\section{Source}

National Cancer Institute. Skin Staple. NCI Thesaurus. Code C148064.

A type of surgical staple designed to close skin wounds. 